Pensamiento Crítico Vol. 18 № 1, pp. 131-142

\title{
Algunas notas a considerar en el análisis monetario de los ciclos económicos
}

Pablo Rivas Santos*

\section{RESUMEN}

El presente artículo describe las explicaciones monetarias de los ciclos económicos, considerando que la expansión del crédito ocurre mediante la excesiva emisión primaria y por ende la excesiva concesión de créditos bancarios efectuados respectivamente por el $\mathrm{BCR}$ y los bancos.

Los obstáculos con que ha tropezado la explicación monetaria de las crisis cíclicas son de carácter teórico y político.

Las continuas alzas y bajas de la actividad económica ; y la inevitable secuencia de auges y depresiones, son efectos provocados por los reiterados intentos de reducir el interés mediante la expansión del crédito. Es inevitable el colapso final del auge generado mediante la expansión del crédito. Solo cabe optar entre provocar más pronto la crisis poniendo fin a la expansión del crédito ; o dejar que la crisis del sistema monetario se produzca un poco más tarde.

* Profesor de Economía e Investigador del Instituto de Investigaciones Económicas de la Facultad de Ciencias Económicas de la Universidad Nacional Mayor de San Marcos. 


\section{Pensamiento Crítico Vol. I8. N I}

En la explicación monetaria de los ciclos económicos ; el BCR y los bancos consideran pernicioso el nivel del interés determinado por el mercado, por lo que cabe provocar una rebaja del interés mediante la expansión del crédito. Esta medida provocará los ciclos económicos.

Así, el período 1992-2012 reflejó un continuo progreso económico; una y otra vez interrumpido por auges y depresiones. Las estadísticas recogen esas fluctuaciones contrarias a la tendencia general hacia un continuo aumento del capital invertido y un permanente incremento de la producción.

Palabras Claves: Ciclos económicos, tasas de interés, expansión del crédito, auges, depresiones.

\section{ABSTRACT}

This article describes the monetary explanations of business cycles, considering that credit expansion occurs through excessive monetary base and hence excessive bank lending.

The obstacles encountered by the monetary explanation of the cyclical crises are theoretical and political.

The constant ups and downs of economic activity, and the inevitable sequence of booms and busts, are effects caused by repeated attempts to reduce the interest by credit expansion. Inevitably the final collapse of the boom generated by credit expansion. One can only cause soon choose between ending the crisis credit expansion, or let the monetary system crisis occurs a little later.

On the monetary explanation of economic cycles and banks BCR considered pernicious interest level determined by the market, so it should cause a reduction of interest by credit expansion. This measure will lead to economic cycles.

Thus, the 1992-2012 period reflected a continued economic progress and again interrupted by booms and busts. The statistics reflect these fluctuations contrary to the general trend toward a continued increase in investment and a constant increase in production.

Keywords: Economic cycles, interest rates, credit expansion, booms, depressions. 


\section{Pablo Rivas Santos}

\section{INTRODUCCIÓN}

Todo proceso productivo requiere un período de producción y para llevarlo a cabo se requieren ahorros. El ahorro proviene de liberar recursos del consumo, de manera que estén disponible para invertirlo en formación y mantenimiento de capital y para ofrecer recursos que mantengan empleados a aquellos que trabajan en el proceso productivo.

El ahorro surge de las preferencias intertemporales de los participantes en el mercado, quienes están dispuestos a renunciar al consumo presente de recursos ; para transferirlos a aquellos que desean usar esos recursos en procesos productivos. La interacción entre oferentes y demandantes por esos recursos genera el interés de mercado que balancea el ahorro y la inversión. Al mismo tiempo, el ahorro disponible pone límite al período de producción; dada la cantidad de fondos ahorrados disponibles.

El dinero hace de intermediario en las transacciones ( que incluye la transferencia de ahorros hacia potenciales prestatarios e inversionistas ). La gente ahorra en forma de ingresos monetarios no gastados en el consumo. La gente deja parte de sus ahorros monetarios como depósitos en bancos ( que hacen de intermediarios financieros en las transacciones intertemporales del mercado ).

Los bancos reúnen esos ahorros monetarios de la gente y lo prestan a prestatarios confiables a la tasa de interés que prevalece en el mercado y que equilibra la oferta de ahorro y la demanda de inversiones. Estos prestatarios utilizan esos ahorros para ingresar al mercado y demandar recursos y trabajo, ofreciendo precios monetarios para comprarlos o contratarlos. Por ello la disminución de la demanda de dinero de los consumidores para tenerlo en cartera y los menores precios de los bienes de consumo debido al ahorro ; y el aumento de la demanda de recursos y los mayores precios de los bienes de producción debido a la inversión ; actúan como la forma en que el mercado acomoda y reasigna recursos para fines de consumo para destinarlos a procesos de producción intensivos en capital. 


\section{Pensamiento Crítico Vol. I8. No I}

\section{DESEQUILIBRIO EN EL PROCESO AHORRO-INVERSIÓN}

Porque el dinero sirve de vínculo intermediario ; al conectar las decisiones de ahorro con las decisiones de inversión, se produce un desequilibrio en el proceso ahorro-inversión.

Supongamos que el ahorro de un país es suficiente solo para financiar procesos productivos de un año de duración.

Ahora supongamos que en ese país el $\mathrm{BCR}$ aumenta la cantidad de dinero a disposición de los bancos para que otorguen créditos. Para atraer prestatarios, los bancos reducen la tasa de interés a la que otorgan créditos.

Esa menor tasa de interés causada por esa expansión monetaria ; elevará el valor presente de los proyectos de inversión con mayores períodos de tiempo.

Ahora supongamos que, en consecuencia, los prestatarios llevan a cabo proyectos de inversión con períodos de producción de dos años de duración.

Dado que ahora se demandan más recursos y trabajo para esos proyectos de inversión de dos años de duración ; una parte de los factores de producción serían alejados de esos proyectos de inversión de un año de duración. Como resultado, al cabo del primer año, habrá menos bienes de consumo disponibles para ser vendidos a los consumidores. Al haber menos bienes de consumo en el mercado, aumentará su precio y los consumidores se verían obligados a disminuir sus compras de esos bienes de consumo. Los consumidores se verían forzados a ahorrar, deberían consumir menos en el presente y esperar hasta que : concluya el segundo año; y los proyectos de producción de dos años de duración hayan sido concluidos para que haya una mayor oferta de bienes de consumo.

Al mismo tiempo, esa mayor oferta monetaria para recursos y bienes ; tendería a hacer que aumente los precios y, en consecuencia, el país experimentaría una inflación durante este proceso. Si el BCR repitiera el aumento de la oferta monetaria período tras período, el resultado sería un proceso acumulativo de aumento de precios. 


\section{CRÉdito DE TRANSFERENCIA - CRÉDITO CREADO}

Hay dos tipos de créditos que se ofrecen en el mercado : crédito de transferencia y crédito creado.

Si no se produjera ningún aumento en la oferta monetaria ; entonces todos los ahorros monetarios provenientes de los ingresos monetarios representarían una transferencia del control del mercado de recursos y trabajo de los que reciben esos ingresos monetarios a los potenciales inversionistas. Los ahorristas habrán prestado una cantidad real de recursos, representados por el valor monetario de esos recursos, para actividades de inversión. Este crédito de transferencia de recursos reales para fines de inversión sería devuelto a los ahorristas ( con el interés acordado ). Entonces ese dinero devuelto tendría la capacidad para comprar una mayor cantidad de bienes para fines de consumo. Y los proyectos de inversión llevados a cabo con el crédito de transferencia tendrían períodos de tiempo consistentes con los ahorros disponibles y con el período en que se realizaron los créditos.

Sin embargo, el BCR y los bancos tienen la capacidad para perturbar este equilibrio entre ahorro e inversión mantenido a la tasa de interés de mercado. Por su capacidad para expandir la oferta monetaria, el BCR y los bancos tienen el poder de crear crédito.

En las transacciones de mercado ; el crédito creado es indistinguible del crédito de transferencia.

El crédito creado representa unidades adicionales de dinero que son intercambiables junto con las otras unidades de dinero ofrecidas en el mercado; a cambio de bienes. Por ello esas unidades adicionales de dinero son tan aceptadas (en las transacciones de mercado) como las unidades de la oferta monetaria existente antes de esa expansión monetaria.

Sin embargo, existe una diferencia : no disminuye la demanda de bienes de los consumidores (que ocurre normalmente ante la decisión de ahorrar más que antes) para compensar el aumento de la demanda de recursos y trabajo de los inversionistas que han tomado ese crédito creado que se les ofrecía en el mercado de crédito. 


\section{Pensamiento Crítico Vol. I8. Nº}

Así, una expansión monetaria crea una crisis económica y genera una serie de eventos llamados ciclos económicos.

\section{EL ROL DE LA NO NEUTRALIDAD DEL DINERO EN EL ANÁLISIS DE LOS CICLOS ECONÓMICOS}

Con el crédito creado, los inversionistas atraerían recursos y trabajo de proyectos de inversión de corto plazo ( y de la producción de bienes de consumo ) para iniciar proyectos de inversión de largo plazo. Estos inversionistas se convierten en receptores de primera vuelta del crédito creado.

Para atraer recursos y trabajo e iniciar proyectos de inversión de largo plazo, esos inversionistas ofrecen mayores precios por los Factores de producción requeridos, para alejarlos de sus usos alternativos en la economía. Ese crédito creado pasa a estos Factores de producción en forma de mayores ingresos monetarios. Estos Factores de producción se convierten en receptores de segunda vuelta de ese crédito creado. Por lo tanto, aumentaría, su demanda de bienes de consumo en la misma proporción de su ingreso.

Como resultado, los precios de los bienes de consumo empezarían a subir. Como se había reasignado los recursos, alejándolos de la producción de bienes de consumo, hay menos bienes de consumo disponibles en el mercado, lo que intensifica el aumento de precios de esos bienes de consumo. Como esos factores de producción gastan sus mayores ingresos en bienes de consumo, ahora aquellos Productores de bienes de consumo se convierten en receptores de tercera vuelta de ese crédito creado.

Ahora esos productores de bienes de consumo aumentan su demanda de aquellos mismos factores de producción escasos para reatraerlos hacia el sector de bienes de consumo y hacia aquellos proyectos de inversión de corto plazo para satisfacer la mayor demanda de bienes de consumo. Así, esos mismos factores de producción que ahora vuelven a ser usados en la producción de bienes de consumo; se convierten en receptores de cuarta vuelta de ese crédito creado.

Aquellos inversionistas que inicialmente habían tomado ese crédito creado ; ahora se encuentran con dificultades para continuar y finalizar sus proyectos de inversión 


\section{Pablo Rivas Santos}

de largo plazo ; dados los crecientes costos de continuar empleando las cantidades requeridas de factores de producción que ahora están regresando hacia los sectores de bienes de consumo. Entonces comienza a emerger la crisis a medida que cada vez más proyectos de inversión de largo plazo no pueden ser continuados por problemas financieros. La demanda por más créditos para continuar con esos proyectos de largo plazo iniciados presiona la tasa de interés a la alza, creando una crisis aún mayor en los sectores de inversión. La fase expansiva del ciclo económico ahora se transforma en una fase contractiva del ciclo, a medida que un número creciente de proyectos de inversión colapsan, sean dejados incompletos, y resulten en una mala inversión de capital en proyectos de inversión largos y económicamente insostenibles.

La única manera para que esos proyectos de inversión puedan se temporalmente salvados sería que el $\mathrm{BCR}$ aumente nuevamente la oferta monetaria, creando más crédito. Pero esto reiniciaría el mismo proceso con el mismo resultado inevitable.

Si el BCR intenta impedir ese resultado inevitable ; a través de cada vez mayores aumentos de la oferta monetaria, el resultado final sería una creciente inflación que amenazaría con la destrucción del sistema monetario del país.

Así, las causas del ciclo económico se encuentra en la manipulación del dinero y del crédito por parte del BCR y los bancos.

\section{EXPLICACIÓN MONETARIA DE LOS CICLOS ECONOMICOS}

En Perú en 1996, para prevenir la recurrencia de las crisis económicas que aparecía por el auge a través de la expansión del crédito ( la excesiva emisión primaria de dinero y la excesiva concesión de crédito bancario ) se aprobó una legislación que restringía la excesiva emisión primaria de dinero y regulaba la expansión del crédito provocado por la excesiva concesión de crédito bancario.

\section{Efectos de la expansión monetaria sobre la producción y los precios.}

Al emitir dinero adicional ; el BCR y los bancos están en posición de expandir considerablemente el crédito. Esa emisión de dinero adicional les permite expandir el crédito más allá del límite establecido por sus propios activos. El BCR y los bancos 


\section{Pensamiento Crítico Vol. I8. Nº}

intervienen en el mercado como oferentes de crédito adicional y así producen una reducción del interés, que cae por debajo del nivel en que estaría sin su intervención. Esa reducción del interés estimula la actividad económica ; porque Proyectos que no eran rentables ( si el interés no se hubiera reducido por el BCR y los bancos ) y que, por tanto, no se hubieran realizado ; ahora son rentables y se inician. Esta situación más activa de los negocios conduce a una demanda creciente de factores de producción y trabajo. Los precios de los factores de producción y los salarios suben, y esa subida de salarios conduce a un aumento de los precios de los bienes de consumo. Si el BCR y los bancos evitaran una adicional expansión del crédito y se limitaran a lo que ya han hecho, el auge terminaría rápidamente. Pero el BCR y los bancos no se desvían de su curso de acción; y continúan expandiendo el crédito en mayor escala, y los precios y los salarios continúan subiendo en forma correspondiente.

Sin embargo, este movimiento ascendente, no puede continuar indefinidamente ; porque los factores de producción y la mano de obra disponibles no han aumentado ; lo único que ha aumentado es la cantidad de dinero. estos factores de producción y la mano de obra que se desvían hacia las nuevas empresas; han sido sustraídos de otras empresas. El país no es lo suficientemente rico como para permitir la creación de nuevas empresas sin sustraer factores de producción y mano de obra de otras empresas. En tanto y en cuanto la expansión del crédito continúa ; esto no se notará, pero esta expansión no puede continuar indefinidamente. Porque si se evita el freno de ese movimiento ascendente (y el colapso de los precios que resultaría de ello) mediante la creación de más y más crédito, se obtendría un continuo y cada vez más rápido aumento de precios. Pero la inflación y el auge pueden continuar suavemente en tanto y en cuanto la gente piense que ese movimiento ascendente de precios terminará en el futuro cercano. En cuanto la gente se da cuenta de que no hay razón para esperar el fin de la inflación, y que lo precios continuarán subiendo, aparecerá el pánico. Nadie quiere mantener dinero, porque su tenencia implica pérdidas mayores de un día para otro; todos se apresuran a cambiar su dinero por bienes : la gente compra bienes que no necesita con urgencia; sin considerar el precio, tan solo para deshacerse del dinero. Este fenómeno que ocurrió en Perú ( que siguió una política de prolongada inflación ) es conocido como la huída hacia valores reales. Los precios de los bienes crecieron aceleradamente como también el precio del dólar, mientras que el precio de la moneda nacional se desplomaba. El valor de la moneda colapsó. 


\section{Pablo Rivas Santos}

Por el contrario, si el BCR y los bancos decidieran frenar la expansión del crédito a tiempo para prevenir ese colapso de la moneda ; y si así se pusiera un freno al auge ; se verá que la falsa impresión de rentabilidad creada por la expansión del crédito ha conducido a inversiones injustificadas. Muchas empresas que se habían iniciados gracias a la reducción artificial del interés, y que se habían sostenido gracias al incremento artificial de los precios, ya no son rentables. Algunas empresas reducen su escala de operación, otras cierran o quiebran. Los precios se desploman; la crisis y la depresión le siguen al auge. La crisis y el período de depresión son la culminación del período de inversiones injustificadas ocasionadas por la expansión del crédito. Las empresas que deben su existencia al hecho de que alguna vez parecían rentables en las condiciones artificiales creadas en el mercado por la expansión del crédito y el incremento de los precios derivado de éste, han dejado de ser "rentables". El capital invertido en estas empresas se pierde en la medida de que se encuentra hundido. La economía debe adaptarse a estas pérdidas y a la situación que resulta de ella. En este caso, lo que debe hacerse, es reducir el consumo ; y, economizando, construir nuevos fondos de capital para que el aparato productivo se adapte a las necesidades actuales y no a las necesidades artificiales que nunca se hubieran manifestado y que nunca se hubieran considerado como reales ; excepto como consecuencia del falso cálculo de rentabilidad basado en la expansión del crédito.

El auge artificial ha sido creado por la expansión del crédito ; y la reducción del interés es consecuencia de la intervención del BCR y los bancos. Durante el período de expansión del crédito ; el BCR y los bancos elevaron progresivamente el interés. Así, desde una perspectiva aritmética el interés termina siendo más elevada de lo que había sido al comienzo del auge. Sin embargo, esa elevación del interés es insuficiente para restablecer el equilibrio en el mercado y para frenar el auge insaludable. Porque en un mercado donde los precios suben continuamente; el interés debe incluir ( además del interés sobre el capital ) un elemento que represente la compensación por el alza de precios que ocurre durante el período del préstamo. Si los precios suben continuamente y si el prestatario ( como resultado de esto ) obtiene una ganancia adicional por la venta de bienes que compró con dinero prestado, ese prestatario estará dispuesto a pagar un mayor interés de lo que hubiera estado en un período de precios estables. Por otro lado, el prestamista no estará dispuesto a prestar bajo estas condiciones, a menos que el interés incluya una compensación por las pérdidas que significa la disminución en el poder adquisitivo de la moneda para los prestamistas acreedores. Si el BCR y los 


\section{Pensamiento Crítico Vol. I8. Nº}

bancos no toman en cuenta estas condiciones ( al establecer el interés que solicitan los prestamistas acreedores ) su tasa debería ser considerada como sostenida a un nivel artificialmente muy bajo, aun si desde una perspectiva aritmética pareciera más alta de la que prevaleciera bajo condiciones "normales". Así, en Perú en 1989 un interés de $300 \%$ se consideraba muy baja debido a la acelerada depreciación de la moneda nacional.

Cuando aparece la depresión del ciclo económico como resultado de la contracción monetaria, resulta muy difícil obtener préstamos debido a la restricción del crédito. Consecuentemente el interés se dispara como resultado del pánico repentino. ( interés que bajará nuevamente ). Luego ( en el período de depresión ) un interés bajo no tiene éxito en estimular la actividad económica. La reserva dineraria de la gente crece y los fondos líquidos se acumulan, sin embargo la depresión continua. En esta crisis esa acumulación de reservas inactivas toman proporciones extraordinarias porque la gente prefiere mantener sus fondos de una forma tal que les permita proteger su dinero de las pérdidas inherentes ante una eventual devaluación mediante una rápida conversión a una moneda que no esté amenazada por una perspectiva de la devaluación. Así la gente no quiere atarse ( a través de inversiones permanentes ) a una moneda que esté amenazada por una perspectiva de la devaluación. Por ello permiten que sus cuentas bancarias crezcan aun cuando obtienen un interés muy bajo.

Otro factor que prolonga el período de depresión es la rigidez salarial. Los salarios suben en los períodos de expansión del crédito. En los períodos de contracción del crédito deberían caer, en términos monetarios y reales. Pero al tener éxito la política sindical en prevenir una reducción de los salarios durante el período de depresión, convierte el desempleo en un fenómeno masivo y persistente. Más aún, esta política sindical posterga indefinidamente la recuperación. Una situación normal no puede retornar hasta que precios y salarios se adapten a la cantidad de dinero en circulación.

\section{CONCLUSIONES}

La gente tiene razón al considerar el fin del auge y la crisis ( como consecuencia de la política del BCR y los bancos ). El BCR y los bancos por algún tiempo podrían retrazar los desarrollos desfavorables. Podrían haber continuado su política de expansión del crédito por un tiempo más. Pero no podrían persistir en ella indefinidamente sin arriesgar 


\section{Pablo Rivas Santos}

el colapso del sistema monetario. El auge ocasionado por la política del BCR y los bancos de expandir crédito terminará tarde o temprano. A menos que estén dispuestos a que su política destruya el sistema monetario ; el BCR y los bancos deben cortar el auge ; antes de que ocurra la catástrofe. Cuanto más largo sea el período de expansión del crédito y más larga sea la demora del BCR y los bancos en cambiar su política, peores serán las consecuencias de las malas inversiones y de la desordenada especulación característica del auge y, como consecuencia, más largo será el período de depresión y más incierta la fecha de recuperación y el retorno a la actividad económica normal.

Estimular la actividad económica mediante una nueva expansión del crédito ; que permita terminar con esa depresión y generar una recuperación o por lo menos un retorno a las condiciones normales; podrían vencer las dificultades del momento ; pero producirían una situación peor en un futuro cercano.

Por lo tanto, los intentos de reducir artificialmente el interés, mediante la expansión del crédito, producirá resultados temporales, y que la recuperación inicial será seguida de una declinación ; que se manifestará en una paralización de la actividad económica. La economía no podrá desarrollarse armoniosamente y regularmente a menos que se abandonen las medidas artificiales que interfieren con el nivel de precios, salarios, $e$ interés determinadas por las fuerzas económicas del mercado.

No es tarea del BCR y los bancos remediar los efectos de la escasez de capital o los efectos de las erróneas políticas de expansión del crédito. Es desafortunado que el retorno a una situación económica normal se demore por perniciosas políticas de estrangular el comercio ; sin dejar de mencionar la rigidez salarial. Pero esta situación no será corregida a través de políticas de expansión del crédito.

\section{BIBLIOGRAFIA}

1. Barro Robert J. Macroeconomía. Alianza editorial. Segunda edición 1990.

2. Friedman Milton. Moneda y desarrollo. Editorial Ateneo. 1985

3. Friedman Milton. Teoría de Precios. Segunda Edición 1976. 


\section{Pensamiento Crítico Vol. I8. Nº}

4. Friedman Milton. Nueva reformulación de la teoría cuantitativa del dinero.

Editorial Continental.

5. Friedman Milton. Reforma bancaria y programa de estabilización.

6. Friedman Milton. Un Marco Teórico del análisis Monetario. CEMLA 1970.

7. Johnson Harry. Ensayos de economía monetaria Amorrurtu editores. Segunda Edición 1970.

8. Kemmerer, Edwin Walter. El ABC de la inflación. BCRP.

9. Mundell Robert A. Teoría Monetaria. Ediciones Amorrurtu. Primera Edición 1971.

10. Ropcke, Wilhelm. Economía Política. Alianza Editorial. 1967

11. Murray, Rothbard. Moneda libre y controlada. Centro de estudios sobre la libertad. 1980

12. Von Hayek, Friedrich. Precios y Producción. Mc Graw Hill. 1960

13. Von Hayek Friedrich. Desnacionalización del dinero, Instituto de Asuntos Económicos, Londres, 1978.

14. Von Mises Ludwig. Acción Humana. Fundación Ignacio Villalonga. 1981

15. Von Mises Ludwig. Reconstrucción Monetaria. Centro de estudios sobre la libertad.

16. Von Mises Ludwig. Teoría de la moneda y el crédito. Fundación Ignacio Villalonga. 